\title{
Student Academic Performance: The Role of Motivation, Strategies, and Perceived Factors Hindering Liberian Junior and Senior High School Students Learning
}

\author{
Charles Gbollie and Harriett Pearl Keamu \\ Foundation for Research, Education and Empowerment (FREE) Liberia, Monrovia, Liberia \\ Correspondence should be addressed to Charles Gbollie; charleson20@yahoo.com
}

Received 27 December 2016; Accepted 27 February 2017; Published 20 March 2017

Academic Editor: Jan Elen

Copyright (c) 2017 Charles Gbollie and Harriett Pearl Keamu. This is an open access article distributed under the Creative Commons Attribution License, which permits unrestricted use, distribution, and reproduction in any medium, provided the original work is properly cited.

\begin{abstract}
The nature of motivation and learning strategy use is vital to improving student learning outcomes. This study was intended to explore the motivational beliefs and learning strategy use by Liberian junior and senior high school students in connection with their academic performance. It also solicited students' self-reports about presumed factors hindering their learning. Utilizing a cross-sectional quantitative research design, 323 participants took part in the study from 2 counties. Motivated Strategies for Learning Questionnaire (MSLQ) was adapted and 12 potential learning hindrances were identified and used as instruments. Data analyses were conducted using SPSS 17.0. The results showed the motivational belief component of extrinsic goal orientation as the most preferred belief and test anxiety was the least possessed belief. Rehearsal strategies were found to be the most frequently used, while help seeking was reported to be the least strategy considered. The result also showed significant relationships between the two constructs. In addition, the study found some learning hindrances. A number of conclusions as well as some practical recommendations for action relative to the improvement of student performance have been advanced.
\end{abstract}

\section{Introduction}

Liberia's education sector is undergoing reform. The sector, like many others, was seriously affected as a result of years of civil unrests, resulting in the destruction of learning facilities and lack of qualified teachers as well as libraries and laboratories to promote smooth teaching and learning in Liberia. In addition, the issues of access, quality, governance, and management need to be enhanced for better educational service delivery for improved student learning outcomes. Consequently, the Government of Liberia (GoL) through the Ministry of Education (MoE), partners and donors, have been tackling Liberia's educational challenges for more than a decade now under the current political sphere. For instance, the Global Partnership for Education (GPE) in 2010 awarded a US $\$ 40$ million dollar grant to support Liberia in implementing its education sector plan [1]. The grant provided resources for strengthening the management capacity and accountability in the education sector. Under the grant
189 classrooms were built or rehabilitated; more than one million textbooks and 20,000 teachers' guides distributed to 2,489 schools, approximately 1 million supplementary reading books, 1.4 million supplementary pieces of instructional materials procured, and school grants disbursed to 2,579 schools following their reopening after the Ebola crisis [1]. The funding phased out in June, 2016. Partner organizations like USAID, UNICEF, OSIWA, EU, Save the Children, and Plan International, among others, have also invested and continue to invest millions into different programs in the sector including teacher training and provision of teaching and learning materials.

As a responsibility bearer to educate its citizens, the Liberian government on an annual basis gives budgetary support to the Ministry of Education to run the education sector. This is in support of GoL's constitutional obligation to provide all Liberians equal access to educational opportunities and facilities to ensure the social, economic, and political wellbeing of Liberia [2]. Accordingly, the Liberian Education Law 
requires for Basic Education of the country, which comprises grades 1-9, to be free and compulsory [3], though the compulsion part is not being fully implemented due to limited access to learning facilities, among other constraints. In compliance with Global Standards, Liberia Ministry of Education is working with its partners and relevant stakeholders to align the Sustainable Development Goal 4, which seeks to ensure inclusive and equitable quality education and promote lifelong learning opportunities for all, with the Ministry's Getting to Best Strategies and Education Sector Plan. This further justifies the need for government and partners to continue their support to the sector.

Emphatically, the support being provided by the Liberian government and donors has triggered some achievements including the provision of textbooks, learning materials, teachers' guides, the construction and renovation of schools, and education facilities around the country and the successful implementation of capacity development programs targeting school administrators, teachers, and Parent-Teacher Associations [4]. Despite educational inputs provided to date, the overall academic performance of Liberian students has not been impressive. This is indicative of the incessant drops in the passing marks of 9th and 12th graders in the regional exams, administered by the West African Examination Council (WAEC) Liberia office [5, 6]. In 2013, no candidate passed in the division one category, and of a total of 27,651 candidates who sat May/June, 2014, senior high school certificate exams only 13,349 or $48.26 \%$ pass, respectively [5]. For 2016, 22,671 out of 46,927 students who registered for the exams failed, which constitutes nearly half $(48.46 \%)$ of the total number of students registered [6]. At junior high level, a total of 30,824 students made a successful pass out of the 49,771 that sat for the exams [6].

As a consequence of the deteriorating student performance, the education sector has received serious backlashes from a cross-section of Liberians including President Ellen Johnson Sirleaf who had called for its total overhaul, stressing the need for concerted efforts to address the situation. As an affirmation, Liberian education sector stakeholders at 2015 Joint Education Sector Review (JESR) in Grand Bassa County (one of Liberia's 15 counties) acknowledged the predicament and carved a joint resolution, declaring Liberia's education as a state of national emergency. In their wisdom, extraordinary actions were needed to redeem the sector, reemphasizing the necessity for collectivism to mend the sector. In an apparent response, the Liberian Ministry of Education has set out a number of priorities in this direction; the most paramount among them relates to dealing with underperformance of students by endeavouring to enhance students learning outcomes [4]. However, there is no proven tested model that guarantees that the implementation of the priorities would fully yield the much anticipated improved learning outcomes as they are not empirically driven.

With the numerous inputs invested in Liberia's education up to this point, many Liberians had envisaged substantial improvement in student learning outcomes. On the contrary, this has not materialized. Therefore, this necessitates taking a deeper step forward through empirical means, which may lead to a paradigm shift from the conventional approach of making interventions to evidence-based programming that would rekindle the required holistic positive change the sector continues to desperately yearn for.

Since students are at the core of learning process, a study tailored to their motivations and strategies and factors hindering their learning is imperative as students themselves play pivotal roles in shifting their own learning and acquiring enhanced academic achievement. Accordingly, Pintrich [7] acknowledged that research on student motivation is central to research in learning and teaching settings. Pintrich et al. [8] have demonstrated that positive motivational beliefs positively related to higher levels of self-regulated learning. This study is critical because it delves into Liberian students' motivations and strategies as well as factors hampering their learning. Cognizant of this, Zimmerman [9] stresses that there is a growing pedagogical need to comprehend how students develop the capability and motivation to regulate their own learning. Zimmerman believes that when students monitor their responding and attribute outcomes to their strategies, their learning becomes self-regulated, and they exhibit increased self-efficacy, greater intrinsic motivation, and higher academic achievement. Gasco et al. [10] noted that motivation plays an important role in learning because it greatly explains academic performance. Students are supposedly capable of instigating, modifying, and sustaining information. Further, research showed that students' motivations and strategy use have some impact on student performance [11]. According to Schunk [12], Pintrich thinks students must monitor, regulate, and control their cognition, motivation, and behavior as part of self-regulated learning. According to Pintrich [7], Zimmerman has revealed that students who are self-regulating, who set goals or plans, and who try to monitor and control their own cognition, motivation, and behavior predicated upon these goals are more likely to do much better in school.

Motivation is a fundamental recipe for academic success. It involves internal and external factors that stimulate desire and energy in people to be continually interested and committed to job, role, or subject, or to make an effort to attain a goal. Dornyei [13] argued that motivation explains why people decide to do something, how hard they are going to pursue it, and how long they are willing to sustain the activity. In order words, "motivation is what gets you going, keeps you going, and determines where you're trying to go" [14, p-317]. Alderman [15] indicates that those students who have optimum motivation have an edge because they have adaptive attitudes and strategies, such as maintaining intrinsic interest, goal setting, and self-monitoring. Besides, motivational variables interact with cognitive, behavioral, and contextual factors to upset self-regulation [16].

Furthermore, motivational beliefs are very essential to the academic achievement of students because they help to determine the extent to which students will consider, value, put in effort, and show interest in the task [17-19]. For example, self-efficacy influences how learners feel, think, motivate themselves, and behave [17]. This has been manifested by research, indicating students' problem solving performance significantly relates to their self-efficacy beliefs [20]. According to Zimmerman [21], Collins found highly efficacious 
students to be quickly capable of rejecting faulty strategies, solving more problems, and reworking more previously difficult problems than their less efficacious counterparts. Further, Zimmerman and Martinez-Pons [22] noted that students who displayed greater perceptions of efficacy and used learning strategies progress well in school. Zimmerman and Martinez-Pons added that students' belief about their academic efficacy can provide an essential window for understanding individual differences in learning and motivation. The general expectancy-value model of motivation characterizes motivation into three components: value components that include goal orientation and task value; expectancy components that include self-efficacy and control beliefs; and the effective construct of test anxiety [18], all of which are considered in this study.

On the other hand, learning strategies have to do with steps taken by students to enhance their learning competencies. In the words of Zimmerman [21], self-regulated learning strategies are actions and processes directed at acquiring information or skill that involve agency, purpose, and instrumentality perceptions by learners. Some learning strategy uses include rehearsal, organization, critical thinking, time and study environment management, effort regulation, peer learning, and help seeking [23]. There is a growing evidence about the importance of these strategies due to their bearings on academic performance [21]. This is because research shows that students who use cognitive strategies such as elaboration and organization engage the contents at deeper level and are likely to remember information and retrieve it later [8]. In a study of 404 college students, Al Khatib [11] found that four of the independent variables (intrinsic goal orientation, self-efficacy, test anxiety, and meta-cognitive selfregulated learning) are significant predictors of college students' performance. On the other hand, students who report higher level of test anxiety were less likely to be self-regulating [8].

Cognizant of the fact that these concepts (students' motivations and learning strategies) are teachable, this study was very beneficial because it established Liberian junior and senior school students motivational beliefs and learning strategy use to learn various subjects. It also identified potential hindrances to students learning and proffered suggestions for enhanced academic performance in Liberia. It is foreseen that this research findings would provide better and clearer comprehensibility of Liberian students' motivation and use of learning strategies to help students, administrators, and policymakers improve teaching and learning through the development or alignment of policies and programs in the interest of nation building.

\section{Key Research Questions}

(1) What motivational beliefs are held by Liberian junior and senior high school students to learn?

(2) Which strategies do Liberian students prefer in their quest to learn?

(3) Does there exist relationship between students' motivations and strategy use?
(4) What factors do Liberian students think are hindering their learning?

Hypothesis. From the literature reviewed, we can generally hypothesize that the types of motivations and strategy use are responsible for the decline in Liberian students' academic performance, particularly for takers of WAEC exams. Our specific hypotheses include the following.

R.Q.1. Liberian junior and senior high school students were less self-efficacious and would be extrinsically motivated to learn.

R.Q.2. Students preferred rehearsal and organization strategies most, while critical thinking and effort regulation were least preferred strategies.

R.Q.3. Students' motivational belief components showed relationship with strategy use components in learning expedition.

R.Q.4. Poor learning facilities and social media will be the most reported challenges hindering students learning, while worrying about life challenges and distance to and from school are the least factors hampering students learning.

\section{Materials and Methods}

2.1. Participants. Utilizing a cross-sectional quantitative research design, 323 participants took part in this study. Of the population, 162 were male and 161 female. They were drawn from eight public schools, comprising 182 (56.3\%), and 7 private schools with 141 (41.3\%) participants from Montserrado and Margibi counties. The schools were selected in consideration with different characteristics of students enrolled. Participants were randomly selected with the participation of exclusively grades $8-12$, at most 10 students per class. On purpose, majority of the participants $(86.7 \%)$ were 9,10 , and 11 grade students between ages 13 to 24 years and above in consideration with their reading comprehension to meticulously and objectively respond to research questions, and time left before they complete high school.

2.2. Research Instruments. The Motivated Strategies for Learning Questionnaire (MSLQ) [23], which seems to represent a useful, reliable, and valid means for assessing students' motivation and the use of learning strategies [24], was adapted and used to establish the motivational component (22 items) and strategy use component (30 items), each using a 7-point scale anchored by "not at all true of me" (1) and "very true of me" (7). Scale scores were obtained by computing the average of the item scores within a scale. The internal consistency reliability coefficients for the whole and subdimensions scale range from .55 to .92 . Besides, 12 widely presumed issues were punctiliously identified which could possibly hamper students learning. Participants were required to rank on the scale of 1 to 12 in order of effect on their schooling, what is/are hampering them the most-1 means very serious effect and 12 not very serious effect. 
TABle 1: Coefficient alphas and descriptive statistics for each motivational belief component.

\begin{tabular}{lcccc}
\hline Number & Motivational belief variable & $\alpha$ & $\mathrm{M}$ & $\mathrm{SD}$ \\
\hline 1 & Intrinsic goal orientation & .45 & 5.41 & 1.42 \\
2 & Extrinsic goal orientation & .43 & 5.81 & 1.15 \\
3 & Task value & .43 & 5.78 & 1.00 \\
4 & Control of learning beliefs & .50 & 5.24 & 1.12 \\
5 & Self-efficacy for learning and performance & .48 & 5.71 & 1.03 \\
6 & Test anxiety & .65 & 4.21 & 1.55 \\
\hline
\end{tabular}

2.3. Research Procedure. Liberian junior and senior high school students were allowed to participate in the study before the climax of 2nd semester of academic 2015/2016 which made it nearly full academic year. By this time, it was expected that they possessed some motivational beliefs as well as using strategies aimed at enabling them to possibly progress to the next grade level or fail. At this time, they could scrupulously report on factors that impeded their learning. Consultations were made at national and school levels. The Ministry of Education was consulted on the rationale and purpose of the study; the Ministry indorsed the study and provided a letter of authorization, seeking school authorities' cooperation. The school administrators and teachers were consulted by FREE Liberia, informing them about the purpose of the study and soliciting their acquiescence to allow their students to participate in the research. Students' participation was completely voluntary even though they were assured of the highest degree of confidentiality.

The questionnaire contains clearly written questions on motivational beliefs, learning strategy use, and factors hampering their learning. Data collectors (staff of FREE Liberia) were trained on basic ethics of research and data collection techniques to enhance their skills to perform the task effectively. The questionnaire was pretested. Participants completed the questionnaire within 20 to 30 minutes.

2.4. Data Analysis. To analyze the data, a number of statistical techniques were employed. As it relates to the motivational beliefs and learning strategies of participants, one-way repeated-measures ANOVA was used. Independent samples $t$-test was used to examine if gender differences existed, while correlation analysis was considered to determine the relationship between students' motivational beliefs and learning strategy use. This part of the analyses was conducted using the Statistical Package for the Social Science (SPSS), version 17.0. The factors hindering students' learning were analyzed based on frequency of reports by respondents.

\section{Results and Discussion}

\subsection{Results}

3.1.1. Motivational Beliefs of Liberian Students for Learning. The means and standard deviations of each of the components were found. Table 1 presents descriptive statistical results on the coefficient alphas, means, and standard deviations of each belief component. Extrinsic goal orientation got the highest mean $(\mathrm{M}=5.81, \mathrm{SD}=1.42)$ and Test Anxiety $(\mathrm{M}=$ $4.21, \mathrm{SD}=1.55)$ obtained the least mean.

3.1.2. Learning Strategies of Liberian Students. Descriptive statistics indicating the means and standard deviations were run, which showed mean differences. Rehearsal strategies have the highest mean $(\mathrm{M}=3.84, \mathrm{SD}=.85)$ and affective strategies obtained the lowest mean $(\mathrm{M}=3.10, \mathrm{SD}=.64)$. At this point, making straightforward generalized statements about these mean differences seems unrealistic. This is because it remains unclear as to whether the differences reached statistical significance. On this basis, one-way repeated-measures ANOVA was introduced, which confirmed that the strategy components differ significantly as $[F(6,191)=$ $52.245, p>0.001]$. Table 2 presents detailed results of coefficient alphas, means, standard deviations, and the pairwise comparisons of various strategy components.

From Table 2 results, it must be noted that, at the point of significance level, the component with the higher mean, for instance, rehearsal strategies and effort regulation strategies, the significance was in favor of rehearsal strategies. In addition, it can be clearly pointed out that rehearsal strategies were preferred over effort regulation strategies by participants of the study and this was statistically significant. The significance of the main preferred strategy use (rehearsal) cut across all the components investigated in this study.

The results also pointed out that organization strategies are the second most favored strategies by participants and they have significant mean differences with all other components, except critical thinking strategies $(\mathrm{M}=3.69, \mathrm{SD}=.61)$, and organization strategies $(\mathrm{M}=3.70, \mathrm{SD}=.79), p=-0.004$, and peer learning strategies $(\mathrm{M}=3.68, \mathrm{SD}=.91)$ and organization strategies $(\mathrm{M}=3.70, \mathrm{SD}=.79), p=0.023$.

3.1.3. Relationship between Students' Motivational Beliefs and Learning Strategy Use. Results from the correlation analysis confirmed the existence of both positive relationship (i.e., as one variable increases in value, the other increases also) and negative relationship (i.e., one variable increases in value, the other decreases). Table 3 presents SPSS output on the correlational relationships between motivational beliefs and learning strategy use by Liberian students.

From Table 3, the most reported motivational belief positively correlated significantly with organization, effort regulation, and help seeking strategies but correlated negatively with peer learning strategies of Liberian junior and senior high school students. Intrinsic goal orientation and self-efficacy for learning and performance were all positively correlated with organization, critical thinking, time and study environment management, and peer learning and help seeking strategies. On the other hand, test anxiety negatively correlated with rehearsal, organization, critical thinking time, and study environment management and peer learning, but it was only statistically significant with effort regulation and help seeking strategies.

3.1.4. Gender Differences for Motivational Beliefs and Learning Strategy Use. Table 4 displays descriptive and independent samples $t$-test statistical results of participants' motivational 
TABLE 2: Coefficient alphas, means, mean differences, and one-way repeated-measures ANOVA pairwise comparison results for learning strategies of participants.

\begin{tabular}{|c|c|c|c|c|c|c|c|c|c|c|}
\hline Variable & $\alpha$ & $\mathrm{M}$ & SD & 1 & 2 & 3 & 4 & 5 & 6 & 7 \\
\hline (1) Rehearsal & .54 & 3.84 & .85 & & & & & & & \\
\hline (2) Organization & .52 & 3.70 & .79 & $.139^{* *}$ & & & & & & \\
\hline (3) Critical thinking & .56 & 3.69 & .61 & $.143^{* *}$ & -.004 & & & & & \\
\hline (4) T \& S Env. Mgmt & .54 & 3.51 & .66 & $.335^{* * *}$ & $.192^{* * *}$ & $-.192^{* * *}$ & & & & \\
\hline (5) Effort regulation & .68 & 3.21 & .79 & $.629^{* * *}$ & $.486^{* * *}$ & $.294^{* * *}$ & $-.294^{* * *}$ & & & \\
\hline (6) Peer learning & .56 & 3.68 & .91 & $.166^{* *}$ & .023 & $-.169^{* *}$ & $-.463^{* * *}$ & $.463^{* * *}$ & & \\
\hline (7) Help seeking & .62 & 3.10 & .64 & $.738^{* * *}$ & $.596^{* * *}$ & $.403^{* * *}$ & $.110^{* *}$ & $.572^{* * *}$ & $-.572^{* * *}$ & \\
\hline
\end{tabular}

Note. $\alpha$ is the mean differences between two means; ${ }^{* * *} p<0.001 ;{ }^{* *} p<0.01$.

$\mathrm{T} \& \mathrm{~S}$ Env. Mgmt means time and study environment management.

TABLE 3: Intercorrelations between Liberian junior and senior high school students' motivational beliefs and strategy use.

\begin{tabular}{|c|c|c|c|c|c|c|c|}
\hline \multicolumn{8}{|c|}{ Strategies } \\
\hline Motivation & Rehearsal & Organization & Critical thinking & T \& S Env. Mgmt & Effort regulation & Peer learning & Help seeking \\
\hline \multicolumn{8}{|l|}{ Variable } \\
\hline Intrinsic & .307 & $.261^{* * *}$ & $.118^{*}$ & $.201^{* * *}$ & .101 & $.200^{* * *}$ & $.197^{* * *}$ \\
\hline Extrinsic & .007 & $.119^{*}$ & -.030 & -.029 & $.203^{* * *}$ & $-.190^{* *}$ & $.128^{*}$ \\
\hline Task value & $.171^{* *}$ & $.266^{* * *}$ & .070 & $.156^{* *}$ & -.002 & .069 & .094 \\
\hline Control beliefs & $.160^{* *}$ & .056 & .081 & $.129^{*}$ & .069 & .052 & .004 \\
\hline Self-efficacy & $.342^{* * *}$ & $.293^{* * *}$ & $.289^{* * *}$ & $.159^{* *}$ & -.070 & $.118^{*}$ & $.122^{*}$ \\
\hline Test anxiety & -.093 & -.044 & -.057 & -.097 & $.119^{*}$ & -.095 & $.116^{*}$ \\
\hline
\end{tabular}

Note. ${ }^{* * *} p<0.001 ;{ }^{* *} p<0.01 ;{ }^{*} p<0.05$.

$\mathrm{T} \& \mathrm{~S}$ Env. Mgmt means time and study environment management.

TABLE 4: Results for motivational beliefs and strategy use for gender $(n=323)$.

\begin{tabular}{|c|c|c|c|c|c|c|}
\hline \multirow{2}{*}{ Variable } & \multicolumn{2}{|c|}{ Male } & \multicolumn{2}{|c|}{ Female } & \multirow{2}{*}{$T$} & \multirow{2}{*}{$p$} \\
\hline & M & SD & M & SD & & \\
\hline Intrinsic & 5.42 & 1.50 & 5.40 & 1.33 & .069 & 0.945 \\
\hline Extrinsic & 5.72 & 1.10 & 5.90 & 1.17 & -1.430 & 0.154 \\
\hline Task value & 5.84 & .97 & 5.72 & 1.02 & 1.031 & 0.303 \\
\hline Control beliefs & 5.18 & 1.08 & 5.30 & 1.15 & -.973 & 0.331 \\
\hline Self-efficacy & 5.69 & 1.068 & 5.72 & .99 & -.298 & 0.766 \\
\hline Test anxiety & 4.10 & 1.65 & 4.31 & 1.44 & -1.260 & 0.209 \\
\hline Rehearsal & 3.80 & .93 & 3.90 & .74 & -.998 & 0.319 \\
\hline Organization & 3.79 & .70 & 3.63 & .87 & 1.780 & 0.076 \\
\hline Critical thinking & 3.72 & .55 & 3.68 & .67 & .591 & 0.555 \\
\hline T \& S Env. Mgmt & 3.56 & .72 & 3.45 & .60 & 1.414 & 0.158 \\
\hline Effort regulation & 3.02 & .80 & 3.40 & .74 & -4.445 & $0.001^{* * *}$ \\
\hline Peer learning & 3.79 & .95 & 3.58 & .86 & 2.064 & $0.040^{*}$ \\
\hline Help seeking & 3.05 & .64 & 3.16 & .64 & -1.487 & 0.138 \\
\hline
\end{tabular}

Note. ${ }^{* * *} p<0.001 ;{ }^{*} p<0.05$.

T \& S Env. Mgmt means time and study environment management.

beliefs and learning strategy use in relation to their gender. Female participants obtained higher means for extrinsic goal orientation and rehearsal, the most preferred motivational belief and strategy use in this study, respectively. However, there were slight mean differences for both genders in other beliefs and strategies.
As it can be noticed from Table 4, female participants reported greater extrinsic, control for learning beliefs, selfefficacy, and test anxiety motivational beliefs. Male students had higher mean differences in intrinsic goal orientation and task value. However, the differences did not reach significance for all motivational belief components. 
TABLE 5: Results for factors affecting students for gender $(n=323)$.

\begin{tabular}{|c|c|c|c|c|c|c|}
\hline \multirow{2}{*}{ Variable } & \multicolumn{2}{|c|}{ Male } & \multicolumn{2}{|c|}{ Female } & \multirow{2}{*}{$t$} & \multirow{2}{*}{$p$} \\
\hline & M & SD & M & SD & & \\
\hline Walking about/going out with peers & 2.62 & .77 & 2.58 & .81 & .415 & 0.679 \\
\hline Going to video clubs: movies/sports & 2.58 & .81 & 2.66 & .74 & -.864 & 0.388 \\
\hline Selling/hustling for my daily bread & 1.98 & .99 & 2.31 & .84 & -2.96 & 0.003 \\
\hline Games (phone, PlayStation) & 2.57 & .80 & 2.18 & .99 & 3.78 & 0.001 \\
\hline Working (Job) & 1.87 & .98 & 2.26 & .96 & -3.530 & 0.001 \\
\hline Worries about life challenges (poverty) & 1.52 & .86 & 2.02 & .98 & -4.831 & 0.001 \\
\hline Harassment from teachers/principals/others & 2.22 & .97 & 2.38 & .91 & -1.576 & 0.116 \\
\hline Housework & 2.17 & .99 & 2.09 & .98 & .753 & 0.452 \\
\hline Poor learning environs (chairs, books, teachers) & 1.92 & 1.00 & 2.28 & .94 & -3.251 & 0.001 \\
\hline Nonacademic related punishments & 2.032 & .99 & 2.34 & .91 & -2.835 & 0.005 \\
\hline Long distance to and from school & 1.77 & .94 & 2.08 & .99 & -2.747 & 0.006 \\
\hline Social media (FB, YouTube, Twitter, etc.) & 2.32 & .93 & 2.34 & .92 & -.205 & 0.837 \\
\hline
\end{tabular}

For strategy use, the descriptive statistics on the mean differences showed slight variations in various strategy use. Unlike motivations, two strategy use components showed statistically significant differences, female participants getting the higher mean for the effort regulation strategies (mean = $3.40, \mathrm{SD}=.74)$ than their male counterparts (mean $=3.02$, $\mathrm{SD}=.90) t(323)=-4.445, p(2$-tailed $)=0.001$, and with male participants getting higher mean on peer learning (mean $=$ $3.79, \mathrm{SD}=.95)$ than their female counterparts $($ mean $=3.58$, $\mathrm{SD}=.86) t(323)=2.064, p(2$-tailed $)=0.040$.

3.1.5. Learning Hindrances of Students. To further deepen our understanding of Liberian junior and senior high school students apart from their motivational beliefs and learning strategy use, this study sought to generate students' selfreports about factors hindering their learning. From a list of 12 potential factors, students were required to choose, in order of effect, perceived learning hindrances. Results from frequency analyses showed worrying about life challenges (poverty) with 57.9\% and access to school (distance to and from school) with $48.9 \%$ as the most critical factors affecting students learning. The least reported were peer pressure (going out friends) and video clubs/games with little over $17 \%$. Figure 1 presents the reported hindrances to learning by Liberian junior and senior high school students.

3.1.6. Gender versus Learning Hindrances. When gender was plotted as a variable relative to these hindrances, female students reported higher effect on their learning for most of the factors in comparison with their male counterparts. Table 5 shows descriptive and independent samples $t$-test statistical results of participants in line with gender.

From Table 5, female students showed significant differences for worrying about life challenges (poverty) (female: mean $=2.02, \mathrm{SD}=.98$ and male: mean $=1.52, \mathrm{SD}=.86) t(323)$ $=-4.831, p(2$-tailed $)=0.001$. Additionally, it portrayed significant differences for selling/hustling for daily bread, poor learning environments, none academic related punishments, and distance to and from school in favor of females, indicating that the problems have more adverse effects on their

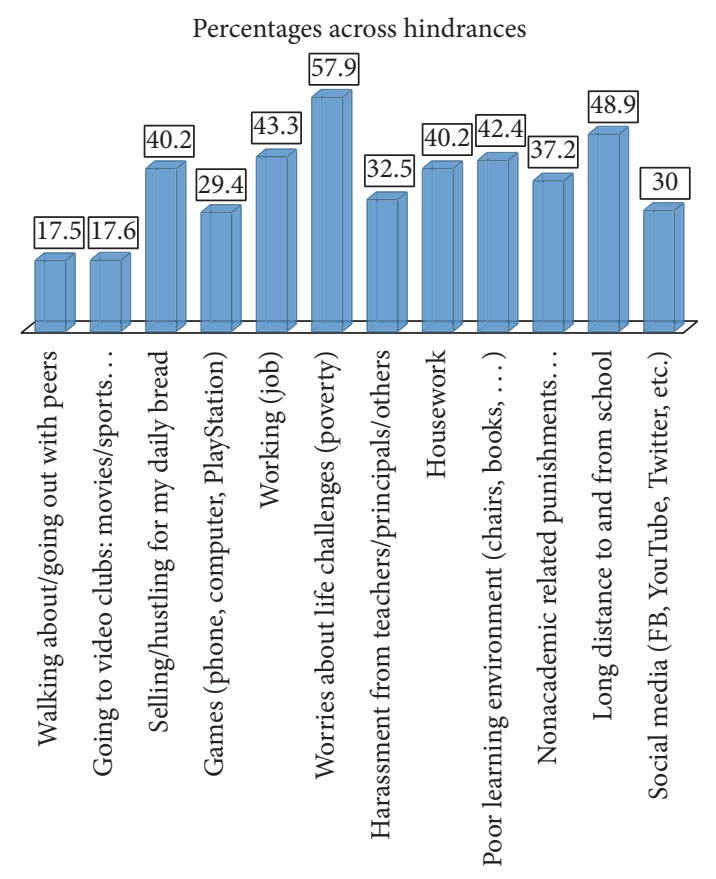

FIGURE 1: Learning hindrances identified by students.

learning as compared to males. However, there was statistically significant difference when it comes to games (phone, computer, and PlayStations) as follows: male (mean $=2.57$, $\mathrm{SD}=.80)$ and female $($ mean $=2.18, \mathrm{SD}=.99) t(323)=3.78$, $p(2$-tailed $)=0.001$.

3.2. Discussion. Academic performance of Liberian students has not been satisfactory to many for nearly a decade now. A sizable number of education stakeholders believes inputs in the sector do not commensurate with student attainment in regional exams. Though their judgement might tend to be subjective and relies exclusively on 9th and 12 graders performance in the WAEC exams, it seems apparently logical. As an old age yardstick for assessing students' performance 
in Liberia, unremitting falloffs despite increased number of trained teachers with better incentive, built or renovated learning facilities, update-to-date textbooks, and so on in comparison with those of early 2000 s are a matter of serious concern. Even though several challenges remain visible in Liberia's education sector, which might still be hampering quality education delivery, much has not been done to delve empirically into underlining factors for the downward trend in Liberian students' academic performance level. FREE Liberia sought to commence a process by understanding the nature of motivation and use of learning strategies to help students, administrators, and policymakers improve learning. As Gasco et al. [10] propounded motivation plays a key role in learning; it largely explains academic performance as it is a construct that integrates both thoughts and feelings. Additionally, the study solicited Liberian junior and senior high school students self-reports regarding factors hindering their learning to inform policy-making and evidence-based programing.

Capitalizing on the decline of students' performance, the study anticipated that Liberian junior and senior high school students would be less self-efficacious and would utilize more rehearsal and organization strategies. They were also hypothesized to show limited use of critical thinking and effort regulation strategies. Further, students' motivational belief components were expected to show relationship with strategy use components as well as gender differences in both constructs. Finally, this research projected several factors deeply hampering students' chances to do well in their academics. The findings of this study, no doubt, provide salient insights into the motivation and strategy use of Liberian students as well as factors hindering their learning and their implications for better student learning outcomes.

The anticipated low self-efficacy for learning and performance hypothesized in this study was confirmed, which was our first aim. Students are found to be more extrinsically motivated, even though they value tasks. This signifies that Liberian students' quest to acquire education is being influenced by external forces. In other words, it can be explained that their devotion to learning different subjects is because of their desires for rewards and fear of penalty from teachers and parents, and not based on their inner aspirations. This result is inconsistent with a study by Marcou and Philippou [20] who found self-efficacy for learning and performance as the most significant belief for learners.

Possibly, the high extrinsic motivation of students is triggered by their conception of education. Going to school might be viewed as a matter of satisfying parents and avoiding negative chastisements from the community. In some instances, parents are constrained to compel compliance for the younger ones to go to school, giving them negative impression that learning is meant to satisfy them. Even though this is done in good faith, it is not enough to guarantee students' success. Total involvement of parents is highly necessary. This study posits that there is disconnection between parents quest for their children to attain quality education and their corresponding involvement into children academics, which could be attributed to high illiteracy rate and purported busy schedules of educated parents. Many parents are not fully involved in their children's learning and see it as a responsibility of the school. This is evident through their nonparticipation in some parent-teacher association activities including meetings. Another factor for students reporting more extrinsic motivation could be as a result of high emphasis being placed on grades. Teachers often consider results from quizzes and tests as the only criterion for judging students' mastery of contents and their abilities to perform better in academic and nonacademic environments. Consequently, students are more interested in getting better test scores because they consider these scores to be the best rewards and a show of academic fulfilment, which in the long run adversely affects their disposition to perform well. As noted by Pintrich [7], Bandura advises students to believe that they are able and that they can and will do well in order to have better changes of remaining motivated in terms of effort, persistence, and behavior. Thus, quality teachers are critical in shifting students learning in a better direction [25] and they need to consider learners' motivation and cognition [8].

Despite high extrinsic motivation displayed, participants showed seemingly high task value and low test anxiety, which are healthy for improved learning outcomes. This means, Liberian students current performance is not as despicable as it may be perceived because they used a variety of motivational beliefs as well. Hence, there are good prospects and big room for improvement.

The second aim of this study was to determine the strategy use by Liberian junior and senior high school students. As hypothesized, students preferred rehearsal and organization strategies. Meaning, participants are mostly interested in repeating the words over and over to themselves to help in the recall of information (rehearsal) [26] and they make much effort to organize learning, for instance, outlining and creating tables, which fall in the category of cognitive learning strategies [23]. This finding is consistent with the extrinsic motivation of students displayed because they tend to memorize notes to pass exams. In addition to the extrapolations, wide use of rehearsal strategies might be influenced by teaching strategies employed in the classrooms. If teachers are not adequately contextualizing and simplifying complex information from abstract to concrete, students may resolve to memorizing and reproducing during exams. On the other hand, this study also finds students help seeking strategies to be the least utilized as they insignificantly report seeking help from peers or instructors when needed, not focusing much on the use of others in learning. Such thing might be hampering their chances of progressing deeply in their learning pursuits as it is necessary ingredient for academic success. Accordingly, students must be motivated to muster courage to solicit assistance whenever necessary.

Moreover, the relationship between motivation and strategy use by participants was confirmed with both positive and negative correlations (see Table 4), indicating how vital motivation is to the kind of strategies used by learners. This is supportive of exposition that the presence of motivation prompts the use of different types of strategies by learners [27]. This finding is overwhelmingly supported by a number of previous studies [27-29] and increases our comprehensibility of motivational beliefs and strategy use. Based on the 
way motivational beliefs influence or show relationship with strategy use in this research, coupled with the available literature, it is argued that motivational beliefs and strategy use are "inseparable academic twins." In this context, the two constructs cannot be separated or one completely goes without the other as students get involved in academic rituals. Motivation can be equated to being a bridge, and strategy use entails walking on the bridge. Therefore, motivation and strategy use relationship must be considered by teachers and school administrators and actions must be employed to suit them. Because when the motivation of students is detrimentally affected, it would have reciprocal effect on students and their learning outcomes.

Relative to gender roles, female participants reported greater extrinsic, control for learning beliefs, self-efficacy, and test anxiety, while male participants had edge when it comes to intrinsic goal orientation and task value. But these differences are infinitesimal as they failed to reach statistical significance for all motivational belief components. We can postulate that motivational beliefs are not ultimately determined by gender. However, this contravenes previous studies that male and female students have significant differences in test anxiety, self-efficacy, and self-regulated learning [10, 11]. The trend of motivation was taken by strategy use, but with a slight difference as two strategy use components (effort regulation and peer learning) were statistically significant in juxtaposition with gender in favor of female participants. Accordingly, females exhibited persisting in the face of difficult or boring tasks (effort regulation) as well as appreciating more learning and using a study group or friends to help learn (peer learning) as compared to their male counterparts. This result is captivating and it is a testament of enormous efforts being put in by education stakeholders to promote enrolment, retention, and completion rates of females aimed at closing gender disparity in Liberia's education sector.

One of the most fascinating findings of this study reveals worrying about life challenges (poverty) and access to school (distance to and from school) as the most perilous factors confronting Liberian junior and senior high school students' learning. This rejects our hypothesis that poor learning facilities and harassment were going to top the list of learning hindrances. Although the finding seems puzzling, it obviously conforms to entrenched high rate of poverty among the Liberian populace. BTI [22] reports that over two-thirds of the population live in extreme poverty, defined as less than \$USD 1.25 per day. This conceivably indicates that some students go to school hungry and without small cash for recess. Besides, some students have to cater for themselves, including paying some associated costs of education. The perceived uncertainty about the future might also be a source of reported worries by participants. Because of high harmful nature of worries (poverty) to academic performance, Capra [30] urged authorities to "treat poverty, a condition that erodes our future and impedes any attempts at educational reform." According to Capra, eradicating poverty and improving education are inextricably connected. Hence, education must be blended with strengthening and giving of hope to students. Liberian parents, school administrators, policymakers, and partners must work out modalities to quench the level of divulged worries among students. Appertaining access (distance to and from school), the finding of this study is consistent with one of the challenges identified by the Ministry of Education to be impeding efforts to have every child in school, according to Gbollie et al. [31]. Although the study particularly concentrated on the urban areas of Montserrado and Margibi counties, access is still a challenge as disclosed by participants. Contrary to presupposition that peer pressure (going out with friends) and video clubs/games are somehow responsible for the underperformance of students, which resulted in some government restrictions, the study establishes that little over $17 \%$ of the participants think it is an issue (see Figure 1).

Since gender remains an important phenomenon in Liberia's education sector, factors affecting students learning were examined in line with gender. Somewhat surprisingly, females reported that nine out of 12 factors have serious negative impact on their learning. This was even statistically significant for worrying about life challenges (poverty) and others (see Table 5), in comparison with male counterparts. Harassment in schools, which is said to be an issue, was among hindrances highly identified by females. Unexpectedly, harassment as a hindrance to learning did not reach significance level for both genders. It is assumed that this is because harassment in this study was treated generally, and it was not limited to sexual harassment, which could be experienced by male students as well. Cognizant of the fact these learning hindrances have more serious consequences for girls' education, addressing these challenges would go a long way in increasing girls' chances for enrolment, retention, and completion. For instance, addressing poor learning conditions, including ensuring good water and sanitation in schools, is strongly needed to heighten girls' chances of staying in school.

\section{Conclusion}

This research has provided valuable contributions to literature. It has increased our knowledge about the types of motivational beliefs and learning strategy use by Liberian junior and senior high school students and how these beliefs and strategies have implications for their academic performance. Specifically, we have been able to establish the stimulating forces (beliefs) and mechanisms (strategies) propelling their progression or retrogression in learning various subjects at school. At the same time, we juxtaposed the belief and strategy constructs as well as investigated participants' genders in the framework of motivational beliefs and strategy use for learning. Furthermore, the research enabled students to identify potential hindrances to their learning in order to derive a way of alleviating the challenges. Drawing from the findings, this study offers a number of conclusions, vital for teaching, learning, and policy-making, particularly in Liberia. The following are conclusions of this research.

(1) Liberian junior and senior high school students possess various motivational beliefs in their quest to acquire education. But they are extrinsically motivated, focusing on rewards and penalties, despite valuing their tasks and being less anxious. 
(2) Rehearsal and organization strategies are of priority to students as they make strides to progress through the academic ladder of high school. Nevertheless, help seeking strategies for asking for assistance from peers or instructors when needed remain the least strategy component considered.

(3) Liberian students with good level of motivational beliefs are capable of using numerous learning strategies. This is, however, contingent on the sort of beliefs they hold. Learners with greater amount of beliefs such as extrinsic and task value are more likely to use strategies including rehearsal and organization.

(4) Being a male or a female does not give any Liberian junior or senior high school student outright advantage. Both males and females can possess different types of beliefs and strategies for learning. Such equitability does augur well towards curbing gender disparity, especially at senior high school level in Liberia.

(5) In spite of efforts being made, students are confronted with serious challenges that might be affecting their academic achievement levels. Students are worried about life challenges (poverty) and future uncertainties. Getting to and from school remains a paramount challenge. Contrary to presumptions, peer pressure (going out with friends) and video clubs/games have less significant effect on students' learning.

(6) Learning hindrances are having more negative blunts on female students. Alleviating these challenges including poor learning facilities would foster increased girls' enrolment, retention, and completion rates in the Liberian school system.

Generally, this study concludes that the performance of Liberian junior and senior high students is moderate in consistence with prevailing learning conditions, and there is a strong need for a paradigm shift to provide the quality of education fervently deserved and desired for all Liberian children. Hence, a number of recommendations and implications for action and future research are proffered.

(1) Based on the significant role of motivation recognized in this study, teachers need to focus keen attention on motivating their students to promote their selfefficacies, always urging students to believe in their abilities to do well, and they (teachers) must also believe in their students. They must also ensure that students learn to ask for assistance whenever necessary. The implication is that if learners are not motivated to enable them to believe in themselves and ask for help, it could affect their dispositions for lifelong learning and their capacities to succeed in various difficult life situations.

(2) Teachers must be trained to integrate the essence of motivational beliefs and the need for students to use all kinds of strategies during instructions. In addition, teachers should assist their students to clearly understand the need for them to build up beliefs like task value, self-efficacy for learning and performance, intrinsic goal orientation, and control for learning beliefs as well as use of critical thinking, effort regulation, and peer and help seeking strategies to enhance their learning process. For instance, teachers can promote students' task value for lessons by stressing the value of education to students' future.

(3) Student evaluation must be meticulous and holistic. Emphasis must not only be placed on grades or rewards as the surest way to academic success, but it must also consider other skills and talents of students. Pupils must be repeatedly reminded to learn for their own good and the good of the society; hence, there is no need for bribery and other academic malpractice to get higher scores. Abolition of fire list in schools is recommended.

(4) Liberian government through the Ministry of Education and partners must intensify efforts to alleviate various problems confronting students including worries about life challenges (poverty), access, poor learning facilities, and harassment in schools. Recreational, school feeding, transportation, continual improvement of schools, and stringent measures against harassment must be assertively supported.

(5) Government through the Ministry of Education should make efforts to train and employ more school counsellors and psychologists to motivate, guide, and mentor students to remain focused and purposeful in their academic pursuits.

(6) Parents must desist from using children as breadwinners; National Government is recommended to compel compliance. Besides, parents must limit workloads given to school going age children and provide sufficient time for them to study their lessons. Effort must be made by both educated and uneducated parents to make time to support their children's learning at home.

(7) There is a glaring need for the Liberian government (Ministry of Education) and partners to undertake or fund systematic research projects (research commissions) to promote better understanding of Liberia's education challenges and prospects. Notfor-profit Liberian research institutions like FREE Liberia, higher education entities, and scholars should be supported morally or financially to routinely conduct empirical research projects in the country and disseminate findings thereof.

(8) Interventions in the education sector must be backed by empirical evidence to enhance possibilities of programs success. Policy-making and programs must be informed by these research findings, and not by mere intuitions or presuppositions.

(9) Finally, despite budgetary constraints, the Liberian government must annually endeavour to augment its education budget to enable the Ministry of Education to transcend from just paying education staff at central and decentralized levels to funding meaningful 
education programs that stimulate quality teaching and learning in schools.

4.1. Limitations and Future Research. Since this study only focused on Liberian junior and senior high school students from two counties (Montserrado and Margibi), results cannot be generalized to other counties. Similar further study is recommended, taking into consideration students from a number of counties with increased sample size preferably focusing on the most vulnerable counties in Southeastern Liberia. Furthermore, this research did not consider all strategy use components by students. There is a need for a study that considers all strategies including metacognitive strategies. Furthermore, this study was unable to get test/exam scores of participants in order to correlate their self-reports with their academic achievements. This could have led to making more generalized and conclusive statements about beliefs and strategies in relation to academic performance of Liberian students. Therefore, future study must consider such combination of both students self-reports and their academic achievements.

\section{Conflicts of Interest}

The authors hereby wish to declare no potential conflicts of interest with respect to the research, authorship, and/or publication of this article.

\section{Acknowledgments}

This research project was funded by the Foundation for Research, Education and Empowerment (FREE), Liberia, in support of quality education in Liberia. FREE Liberia is a registered and duly accredited not-for-profit NGO aimed at improving lives through quality research, education, and empowerment. The authors' sincere thanks and appreciation are due to FREE Liberia's Board members, especially Dr. Michael P. Slawon, Atty. Ramses T. Kumbuyah, and Dr. Rosemarie Terez-Santos, and staff of the organization including Coretta Kialen, Joseph Bernard, M. Freeman Dorker, Mulbah Saywala, David Tagbailee, and Faith K. Kialen for their kind support of, dedication to, and commitment in making this initiative a resounding success. They are also grateful to $\mathrm{Mr}$. Flemmings Fishani Ngwira and other colleagues for their inputs to the final product of this article.

\section{References}

[1] P. Darvas and P. Darvas, Liberia-Global Partnership for Education Grant for Basic Education Project: P117662-Implementation Status Results Report: Sequence 10, World Bank Group, Washington, DC, USA, 2015, http://www.globalpartnership.org/ country/liberia.

[2] The Constitution of the Republic of Liberia, 1986.

[3] Education Law, Education Reform Act of 2011, Title 10, Liberian Code of Laws Revised, Authority of Ministry of Foreign Affairs, Monrovia, Liberia, 2011.

[4] The Ministry of Education Annual Report, Republic of Liberia, 2015.
[5] C. Y. Kwanue, "WAEC Reports 'Appalling Results' in May/June Exams," 2014, http://www.liberianobserver.com/education/ waec-reports-\%E2\%80\%98appalling-results\%E2\%80\%99-mayjune-exams.

[6] A. Worzi, Liberia: WAEC 2016: Worst Results Since 2013, Daily Observer, 2016, http://allafrica.com/stories/201608050714.html.

[7] P. R. Pintrich, "A motivational science perspective on the role of student motivation in learning and teaching contexts," Journal of Educational Psychology, vol. 95, no. 4, pp. 667-686, 2003.

[8] P. R. Pintrich, R. W. Roeser, and E. A. M. de Groot, "Classroom and Individual differences in early adolescents' motivation and self-regulated learning," The Journal of Early Adolescence, vol. 14, no. 2, pp. 139-161, 1994.

[9] B. J. Zimmerman, "Self-regulating academic learning and achievement: the emergence of a social cognitive perspective," Educational Psychology Review, vol. 2, no. 2, pp. 173-201, 1990.

[10] J. Gasco, A. Goñi, and J. D. Villarroel, "Sex differences in mathematics motivation in 8th and 9th grade," Procedia-Social and Behavioral Sciences, vol. 116, pp. 1026-1031, 2014.

[11] S. A. Al Khatib, "Meta-cognitive self-regulated learning and motivational beliefs as predictors of college students' performance," International Journal of Research in Education, vol. 27, pp. 57-72, 2010.

[12] D. H. Schunk, "Self-regulated learning: the educational legacy of Paul R. Pintrich," Educational Psychologist, vol. 40, no. 2, pp. 85-94, 2005.

[13] Z. Dornyei, Motivational Strategies in the Language Classroom, Cambridge University Press, New York, NY, USA, 2001.

[14] R. E. Slavin, Educational Psychology: Theory and Practice, Pearson, New York, NY, USA, 2006.

[15] M. K. Alderman, Motivation for Achievement: Possibilities for Teaching and Learning, Lawrence Erlbaum Associates, London, UK, 2004.

[16] P. R. Pintrich, R. W. Marx, and R. A. Boyle, "Beyond cold conceptual change: the role of motivational beliefs and classroom contextual factors in the process of conceptual change," Review of Educational Research, vol. 63, no. 2, pp. 167-199, 1993.

[17] A. Bandura, "Perceived Self-Efficacy in Cognitive Development and Functioning," Educational Psychologist, vol. 28, no. 2, pp. 117-148, 1993.

[18] E. Yukselturk and S. Bulut, "Predictors for student success in an online course," Educational Technology and Society, vol. 10, no. 2, pp. 71-83, 2007.

[19] N. Mousoulides and G. Philippou, "Students' motivational beliefs, self-regulation and mathematics achievement," The Psychology of Mathematics Education, vol. 3, pp. 321-328, 2005.

[20] A. Marcou and G. Philippou, "Motivational beliefs, selfregulated learning and mathematical problem solving," Group for the Psychology of Mathematics Education, vol. 3, pp. 297-304, 2005.

[21] B. J. Zimmerman, "A social cognitive view of self-regulated academic learning," Journal of Educational Psychology, vol. 81, no. 3, pp. 329-339, 1989.

[22] B. J. Zimmerman and M. Martinez-Pons, "Student differences in self-regulated learning: relating grade, sex, and giftedness to self-efficacy and strategy use," Journal of Educational Psychology, vol. 82, no. 1, pp. 51-59, 1990.

[23] T. G. Duncan and W. J. McKeachie, "The making of the motivated strategies for learning questionnaire," Educational Psychologist, vol. 40, no. 2, pp. 117-128, 2005. 
[24] P. R. Pintrich, D. A. Smith, T. Garcia, and W. J. Mckeachie, "Reliability and predictive validity of the motivated strategies for learning questionnaire (Mslq)," Educational and Psychological Measurement, vol. 53, no. 3, pp. 801-813, 1993.

[25] C. Gbollie and M. David, "Aligning expansion and quality in higher education: an imperative to Liberia's economic growth and development," Journal of Education and Practice, vol. 5, no. 12, pp. 139-150, 2014.

[26] P. R. Pintrich, "The role of metacognitive knowledge in learning, teaching, and assessing," Theory into Practice, vol. 41, no. 4, pp. 219-225, 2002.

[27] R. Schmidt and Y. Watanade, "Motivation, strategy use, and pedagogical preferences in foreign language learning," in Motivation and Second Language Acquisition, Z. Dornyei and R. Schmidt, Eds., University of Hawaii, Second Language Teaching and Curriculum Center, Honolulu, Hawaii, USA, Technical Report \#23, pp. 313-359, 2001.

[28] X. Xu, "The relationship between language learning motivation and the choice of language learning strategies among Chinese graduates," International Journal of English Linguistics, vol. 1, no. 2, 2011.

[29] N.-D. Yang, “The relationship between EFL learners' beliefs and learning strategy use," System, vol. 27, no. 4, pp. 515-535, 1999.

[30] T. Capra, "Poverty and its impact on education: today and tomorrow," http://www.nea.org/assets/docs/HE/TA09PovertyCapra.pdf.

[31] C. Gbollie, E. B. Waydon, and J. Bernard, Free, Compulsory Education: A Case Study in Liberia, Revenue Internationale D'Education Series, 2016, http://www.ciep.fr/en/revue-internationale-deducation-sevres/what-school-teaches-everyone. 


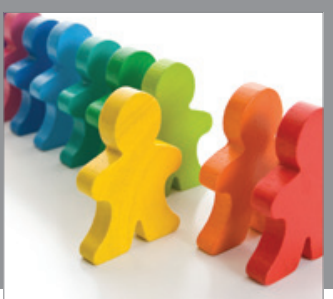

Autism

Research and Treatment
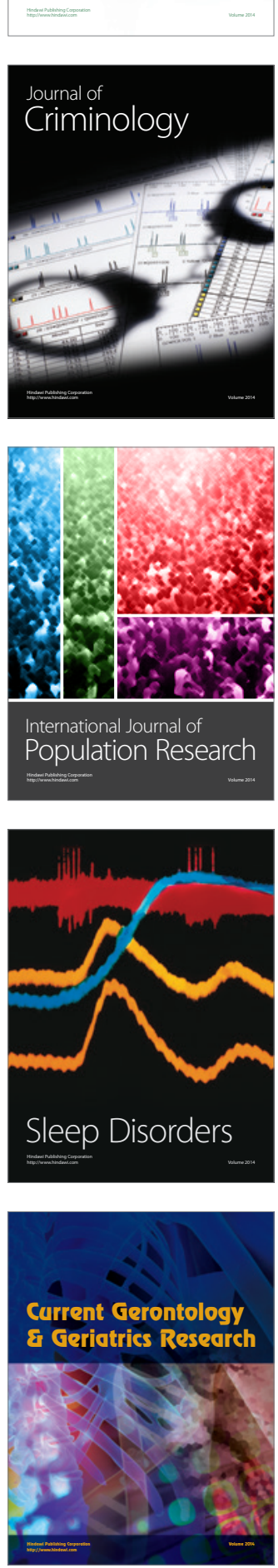

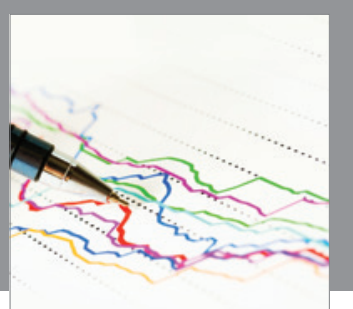

Economics

Research International
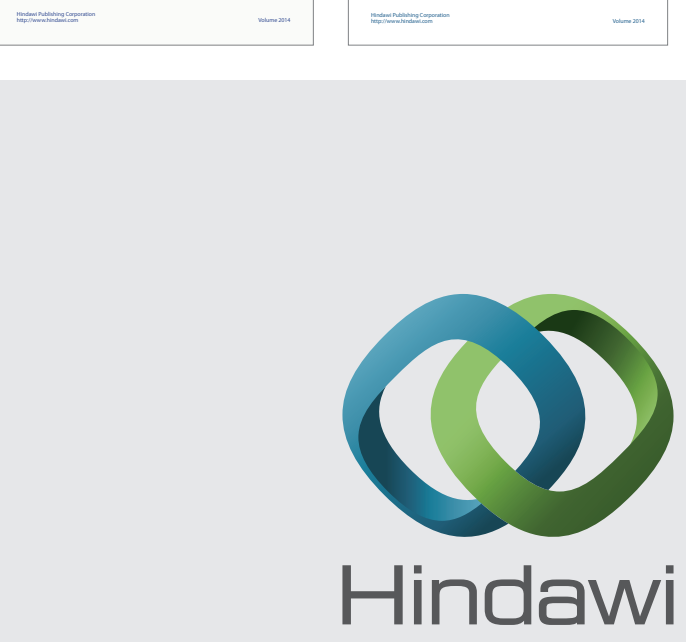

Submit your manuscripts at

https://www.hindawi.com
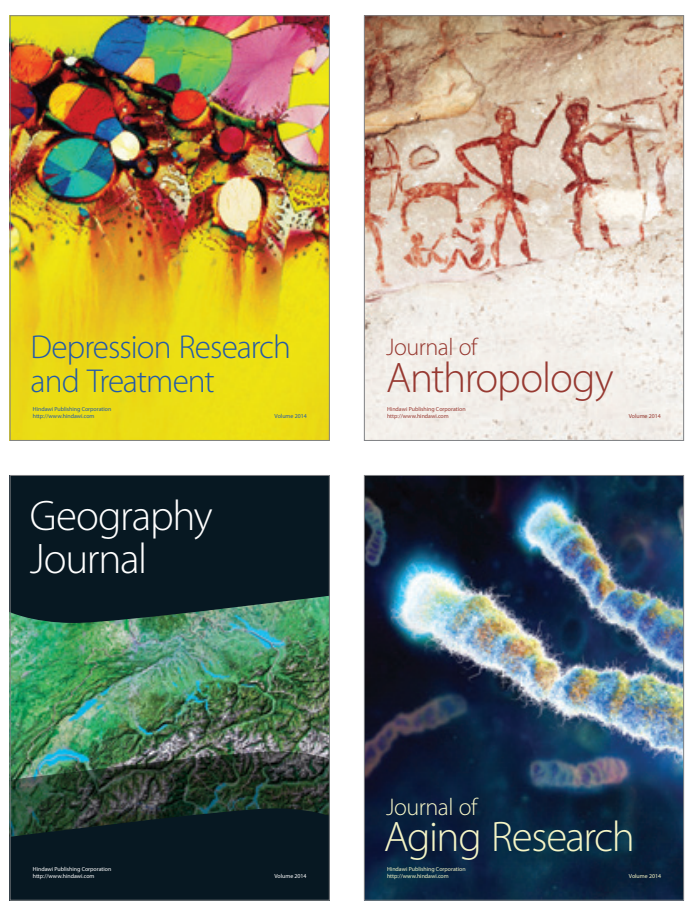
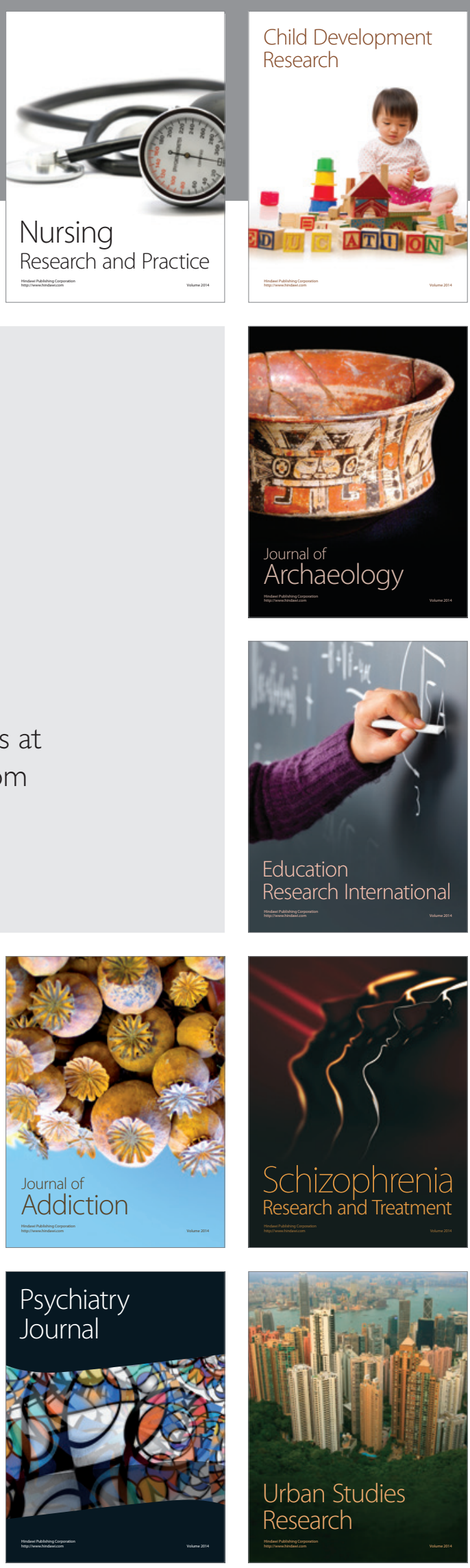